\title{
Bioremediation of phenanthrene-polluted soil using Bacillus kochii AHV-KH14 as a halo-tolerant strain isolated from compost
}

\author{
Rozhan Feizi $^{\circledR}$, Sahand Jorfi ${ }^{*}{ }^{\circledR}$, Afshin Takdastan $^{2}{ }^{(\mathbb{C}}$ \\ ${ }^{1}$ Student Research Committee, Ahvaz Jundishapur University of Medical Sciences, Ahvaz, Iran \\ ${ }^{2}$ Department of Environmental Health Engineering, School of Health, Ahvaz Jundishapur University of Medical Sciences, Ahvaz, Iran
}

\begin{abstract}
Background: Phenanthrene (PHE) is a polycyclic aromatic hydrocarbon (PAH) with crystalline structure of $\mathrm{C} 14 \mathrm{H} 10$, which was produced from incomplete combustion of hydrocarbons and fossil fuels and can cause harmful biological effects. Bioremediation using halophilic bacteria is payed attention over chemical methods due to considerable benefits.

Methods: In the present study, a halo-tolerant bacterium Bacillus kochii strain AHV-KH14 was isolated from municipal compost, and used for the bioremediation of PHE from the contaminated soil. The effects of operational parameters including soil/water ratio, initial inoculum size, PHE concentration, and salinity on the bioremediation performance were investigated.

Results: A biodegradation efficiency of about to $98 \%$ was obtained for PHE concentration of $50 \mathrm{mg} /$ $\mathrm{kg}$ and salinity level of $1.5 \%$. By increasing salinity content PHE concentration, PHE biodegradation rate decreased significantly. It was found that the bioremediation efficiency decreased with increasing PHE concentration. It was also revealed that for the unwashed soil sample, cumulative concentrations of different hydrocarbons played an important role in decreasing the efficiency of bioremediation.

Conclusion: A natural hydrocarbon-contaminated soil sample with total petroleum hydrocarbon (TPH) concentration of $2350 \mathrm{mg} / \mathrm{kg}$ was subjected to bioremediation using the selected conditions of operational parameters, and a biodegradation rate of $17.7 \%$ was obtained.

Keywords: Biodegradation, Soil pollution, Phenanthrene, Bacillus kochii strain AHV-KH14, Compost Citation: Feizi R, Jorfi S, Takdastan A. Bioremediation of phenanthrene-polluted soil using Bacillus kochii AHV-KH14 as a halo-tolerant strain isolated from compost. Environmental Health Engineering and Management Journal 2020; 7(1): 23-30. doi: 10.34172/EHEM.2020.04.
\end{abstract}

\section{Article History:}

Received: 23 September 2019 Accepted: 15 December 2019 ePublished: 13 January 2020

\section{Introduction}

Polycyclic aromatic hydrocarbons (PAHs), as a group of organic compounds, are among the most common contaminants in the environment. PAHs are released into the environment through bringing fossil fuels, such as coal, oil, coal, and natural gas, as well as anthropogenic activities (1). Emissions from the anthropogenic activities, such as the production of plastics, pesticides, and dyes, coal burning power plants, and shipping activities, are considered as the main sources of these compounds in the environment (2). PAHs are mainly produced as a result of incomplete combustion of wood, tobacco coal, oil, and petrol. PAHs are released into the environment in gas and particle phases. Atmospheric PAHs can be deposited to the earth through wet and dry deposition processes. So that, these compounds can be added to surface soil and cause soil contamination (3). Short-term exposure to these compounds is associated with eye irritation, nausea, vomiting, diarrhea, and confusion (4). But there is a growing concern regarding their long-term effects. Previous studies have shown that long-term exposure to PAHs can cause cancer in some individuals. Moreover, the US Environmental Protection Agency (USEPA) has classified several types of PAHs as probably carcinogenic to humans. The presence of PAHs in soil poses serious health threats to human population (5). Phenanthrene (PHE) is one of the most widely used PAHs that has low biodegradability and high persistence in the environment. The USEPA has classified PHE as a priority pollutant. Therefore, they must be removed before being released into the environment. Until now, many technologies, such as solvent extraction, phytoremediation, photocatalytic remediation, electrochemical remediation, thermal destruction, and bioremediation, have been tested for 
the remediation of soils contaminated by hydrocarbons. Biological processes have received many attentions from scientists and researchers due to their less toxicity to the environment, easy maintenance, high-performance, and economic aspects of the contaminated soils remediation. Bioremediation is a biological process used for the treatment of organic pollutants from various media, such as water, soil, air, and surface of materials. In bioremediation, microorganisms or their enzymes are applied to treat and remove organic pollutants from various media (6). Bioremediation, which relies principally on living organisms, especially fungi, bacteria, and plants, is a reliable technique for the degradation of persistent organic pollutants (POPs), such as pesticides, solvents, pharmaceuticals, and PAHs. Bioremediation as a promising technique offers many advantages including low damage to ecosystem, low operating costs, producing few harmful byproducts, and ease of use in different conditions (7). The bioremediation efficiency of microorganisms depends on various parameters, such as pollutant type, microorganism type, substrates, pollutant concentration, and environmental conditions. The selection of suitable species of microorganism with regard to the target contaminant has a dramatic impact on the bioremediation performance (8). So far, various microorganisms like Penicillium chrysogenum, Pseudomonas putida, Coprinellus radians, Tyromyces palustris, Gloeophyllum trabeum, Trametes versicolor, Acinetobacter sp., Pseudomonas sp., Bacillus subtilis, Ralstonia sp., and Microbacterium sp. have been applied for the bioremediation of POPs (9-11). Among them, Bacillus strains have shown high potential to degrade PAHs from surface soil (12). To the best of our knowledge, this is the first report demonstrating the Bacillus subtilis strain AHV-KH14 for the bioremediation of PHE from contaminated soil. Therefore, in the present study, a halotolerant bacterium Bacillus kochii strain AHV-KH14 was isolated from municipal compost, and then, used for the bioremediation of PHE from the contaminated soil.

\section{Materials and Methods}

Materials

HPLC-grade PHE, n-hexane, methanol, trichloromethane, $\mathrm{H}_{2} \mathrm{SO}_{4}$ (95-97\%), $\mathrm{NaOH}$, and all chemicals used in the preparation of culture media were analytical grade and purchased from Merck, Germany. Also, experimental solutions were prepared using deionized water.

\section{Bacterial isolation}

In brief, $100 \mathrm{~g}$ compost produced from municipal wastes was added to a $250-\mathrm{mL}$ flask containing $100 \mathrm{~mL}$ phosphate mineral salt (PMS) medium. The medium was stirred for 20 minutes, and thereafter, allowed to settle. Afterwards, 10 $\mathrm{mL}$ of the supernatant was poured into a flask containing $100 \mathrm{~mL}$ PMS. The PMS medium was prepared using the following formulation $\left(\mathrm{g} \mathrm{L}^{-1}\right)$ : $\mathrm{K}_{2} \mathrm{HPO}_{4}$ : 6.3, $\mathrm{CaCl}_{2} \cdot \mathrm{H}_{2} \mathrm{O}$ : $0.1, \mathrm{MgSO}_{4} \cdot 7 \mathrm{H}_{2} \mathrm{O}: 0.1, \mathrm{MnSO}_{4} \cdot \mathrm{H}_{2} \mathrm{O}: 0.1, \mathrm{FeSO}_{4} \cdot 7 \mathrm{H}_{2} \mathrm{O}: 0.1$, and $1 \mathrm{~mL} / \mathrm{L}$ of micro nutrients medium. The constituents of micro nutrients medium as the following $(\mathrm{g} / \mathrm{L}): \mathrm{H}_{3} \mathrm{BO}_{3}$ : $0.03, \mathrm{CoCl}_{2} \cdot 6 \mathrm{H}_{2} \mathrm{O}: 0.02, \mathrm{ZnSO}_{4} \cdot 7 \mathrm{H}_{2} \mathrm{O}: 0.01, \mathrm{CuSO}_{4} \cdot 2 \mathrm{H}_{2} \mathrm{O}$ : $0.001, \mathrm{Na}_{2} \mathrm{MoO}_{4}: 0.006$. PHE, were used as carbon sources for the isolation of PHE-degrading strains, and added into the culture medium at a concentration of $100 \mathrm{mg} / \mathrm{L} \%$ (V/V) (13). The PHE was added to the culture medium by its solubilization in $\mathrm{n}$-hexane. $\mathrm{NaCl}$ was used to set the salinity of culture mediums at $1.5 \%$. All culture mediums were always sterilized before experiments. For each incubation step, the shaker incubator was set at $37^{\circ} \mathrm{C}$ and $180 \mathrm{rpm}$ for 1 week. By measuring the absorbance value at $600 \mathrm{~nm}$, bacterial growth was daily monitored. The procedure of enrichment was repeated four times by refreshing the culture medium. Pure PHEdegrading bacteria were isolated by dilution of $1 \mathrm{~mL}$ of culture medium ( $10^{-4}$ times), followed by spreading onto specific solid culture medium (PHE-coated PMS agar). Afterwards, solid culture mediums were incubated at $37^{\circ} \mathrm{C}$ for 72 hours (14). The salinity was adjusted to $1.5 \%$. After repetitive streaking, morphologically distinct colonies were compared and isolated according to the growth rate.

\section{S rRNA}

In this study, 16S ribosomal DNA (rDNA) sequencing using universal $27 \mathrm{~F}$ and $1525 \mathrm{R}$ primers of the genomic DNA was used for the genetic identification of the isolated strain (14). The genomic DNA was extracted by boiling (15). Polymerase chain reaction (PCR) was carried out using Biometra thermocycler (Whatman, Biometra, Göttingen, Germany). A $50-\mu \mathrm{L}$ solution containing Lyophilized I-Taq Maxime PCR PreMix (iNtRON Biotechnology, Korea), $41 \mu \mathrm{L}$ double distilled $\mathrm{H}_{2} \mathrm{O}, 5 \mu \mathrm{L}$ extracted DNA, and $2 \mu \mathrm{L}$ of each primer $(10 \mathrm{pmol})$ was applied to perform the reaction of amplification. The PCR conditions were as follows: initial denaturation step $\left(95^{\circ} \mathrm{C}\right.$, 5 minutes) followed by 35 cycles of denaturation $\left(94^{\circ} \mathrm{C}\right.$, 20 seconds), annealing $\left(56^{\circ} \mathrm{C}, 30\right.$ seconds), polymerization $\left(72^{\circ} \mathrm{C}, 90\right.$ seconds), and a final extension step at $72^{\circ} \mathrm{C}$ for 15 min. The purification of the PCR products was carried out using QIAquick Gel Extraction kit (Qiagen, Germany), and direct sequencing in both strands via an ABI PRISM 3730xl DNA Analyzer and the BigDye Terminator v3.1 Cycle Sequencing Kit chemistry (Applied Biosystems, USA) under contract by Bioneer Inc. (South Korea). The edition and assembling of Sanger sequence reads were carried out using DNA Sequence Assembler v4 (2013). The analysis of sequence data was performed using BLASTn from NCBI (http://www.ncbi.nlm.nih.gov), and classified using the EzTaxon server http://ezbiocloud. net/eztaxon. The phylogenetic analysis was performed in MEGA 6.0 by neighbor-joining algorithm using Kimura2-parameter model and 1000-bootstrap replication. 


\section{Soil preparation}

The soil samples required for bioremediation experiments were derived from a contaminated area in the Southwest of Iran, using soil cores from depth of 0-30 cm. Afterwards, the samples were air-dried, sieved $(2 \mathrm{~mm})$, shaken, and rinsed by acetone for the removal of organics, then, sterilized and finally, stored in plastic ice boxes. For synthetically contamination of the soil, the PHE was first solubilized in n-hexane, and then, added at desired levels of 50,100 , and $200 \mathrm{mg} / \mathrm{kg}$ to the samples. The solvent was evaporated under hood during 24 hours. The oxides present in the soil sample was determined using X-ray fluorescence analysis. According to results presented in Table 1, the soil sample was a sandy-clay type based on the texture. It should be noted that a portion of soil sample was kept without any processing as a naturally-contaminated soil sample.

\section{Experimental procedure}

Thirty grams of the synthetically contaminated soil was poured into $500-\mathrm{mL}$ flasks. Operational variables including moisture content (50\%, 100\%, and slurry), PHE concentrations $(50,100$, and $200 \mathrm{mg} / \mathrm{kg})$, salinity $(0.5 \%$, $1 \%, 1.5 \%$, and $2 \%)$, and inoculums size $(5,10,15$, and 20 $\mathrm{mL}$ ), as well as their effects on the biodegradation rate, were investigated using one-factor-at-a-time method $(15,16)$. Experimental samples were shaken at $180 \mathrm{rpm}$ and $37^{\circ} \mathrm{C}$ and the amount of residual PHE and microbial growth were monitored weekly. Soil sample was extracted using EPA method 3550B for the PHE analysis. The residual was solved in $4 \mathrm{~mL}$-hexane for the quantitative analysis. The PHE concentration was determined by gas chromatography (GC) system (Chrompack CP 9001) equipped with a flame ionization detector (FID) using (HP5) capillary column $(30 \mathrm{~m}, 0.32 \mathrm{~mm}$ i.d. and $0.2 \mu \mathrm{m}$ film thickness). Nitrogen was used as a carrier gas at a flow rate of $2 \mathrm{~mL} \mathrm{~min}{ }^{-1}$. The temperature program was as follows: the column temperature was held at $120^{\circ} \mathrm{C}$ for 1 minute, and then, raised to $240^{\circ} \mathrm{C}$ at a rate of $20^{\circ} \mathrm{C} \mathrm{min}^{-1}$, then, held for 1 minute. The injector and detector temperatures were set at 250 and $300^{\circ} \mathrm{C}$, respectively. The PHE recovery rate was about $90 \%$ immediately after spiking. Considering the value of $10 \%$ as non-extracted portion of PHE in

Table 1. Soil characteristics

\begin{tabular}{lccc}
\hline Characteristic & Value (\%) & Characteristic & Value (\%) \\
\hline Sand & 24 & $\mathrm{Na}_{2} \mathrm{O}$ & 1.004 \\
Clay & 37 & $\mathrm{MgO}$ & 2.57 \\
Silt & 39 & $\mathrm{Al}_{2} \mathrm{O}_{3}$ & 11.49 \\
Moisture content & 10.45 & $\mathrm{SiO}_{2}$ & 5.26 \\
$\mathrm{Fe}_{3} \mathrm{O}_{4}$ & 3.98 & $\mathrm{P}_{2} \mathrm{O}_{5}$ & 3.2 \\
$\mathrm{Sr}$ & 3.26 & $\mathrm{~K}_{2} \mathrm{O}$ & 0.02 \\
$\mathrm{Zr}$ & 6.85 & $\mathrm{CaO}$ & 0.006 \\
L.O.I & 51.6 & $\mathrm{Cl}$ & 10.76 \\
\hline
\end{tabular}

the soil, all raw data were multiplied by the factor of 1.1. All experiments were carried out in triplicate. The total petroleum hydrocarbons (TPH) values of the samples were determined with gas chromatography equipped with a flame ionization detector (GC-FID) (Chrompack CP 9001) using (HP-5) capillary column (30 m length, 0.32 $\mathrm{mm}$ inner diameter, and $0.2 \mathrm{~mm}$ film thickness). Bacterial density was evaluated based on the most probable number (MPN) (16). Finally, a set of bioremediation experiments was conducted on the unwashed soil sample under selected conditions. The naturally contaminated soil was also analyzed to determine the quantity and quality of hydrocarbons using gas chromatography mass spectrometry (GC-MS) analysis (Agilent 7890, USA) with HP-5MS capillary column $(30 \mathrm{~m} \times 0.25 \mathrm{~mm} \times 0.25 \mathrm{~mm}$ film thickness, $5 \%$ phenyl-95\% methyl siloxane phase).

\section{Results}

It was revealed that PHE biodegradation was inoculum size-dependent. The trend of PHE biodegradation against time indicated that the seed volume favored biodegradation rate until $10 \mathrm{~mL}$, and higher values of seed size did not enhance the PHE removal. The results of this part are presented in Figure 1. Figure 2 shows the results of the effects of water content on the removal efficiency. The PHE removal rate at different moisture levels of $50 \%, 100 \%$, and $200 \%$ (slurry) were $23 \%, 35.5 \%$, and $62.5 \%$, respectively. Moreover, the effects of soil salinity on the PHE biodegradation rate are shown in Figure 3. As shown in this figure, the removal efficiencies of PHE (initial concentration of $200 \mathrm{mg} / \mathrm{kg}$ ) at the end of day 56 for salinity levels of $0.5 \%, 1 \%, 1.5 \%$, and $2 \%$ were $62.5 \%$, $64 \%, 64.5 \%$, and $32 \%$, respectively. The inhibitory effect of PHE on biomass was not considerable for the PHE concentrations of $50-200 \mathrm{mg} / \mathrm{kg}$. Figure $4 \mathrm{~A}$ shows the effect of PHE concentration on the process performance. The biodegradation rate for the PHE concentrations of 50, 100 , and $200 \mathrm{mg} / \mathrm{kg}$ were $98 \%, 89 \%$, and $64 \%$, at the end of study period. Figure 5 represents the TPH mineralization

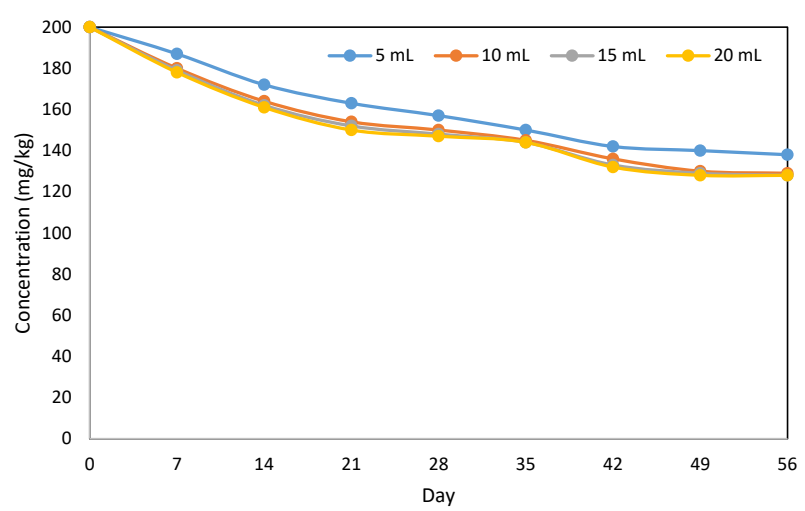

Figure 1. Effect of seed size on the PHE biodegradation in the contaminated soil using Bacillus kochii strain AHV-KH14, moisture: $100 \%$, and salinity: $0.5 \%$. 


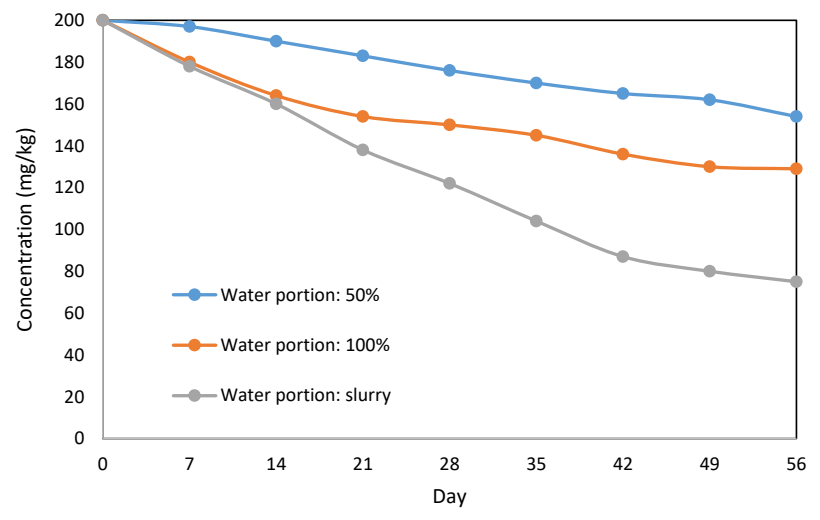

Figure 2. Effect of water content on the PHE biodegradation in the contaminated soil using Bacillus kochii strain AHV-KH14, seed size: $10 \mathrm{~mL}$, and salinity: $0.5 \%$.

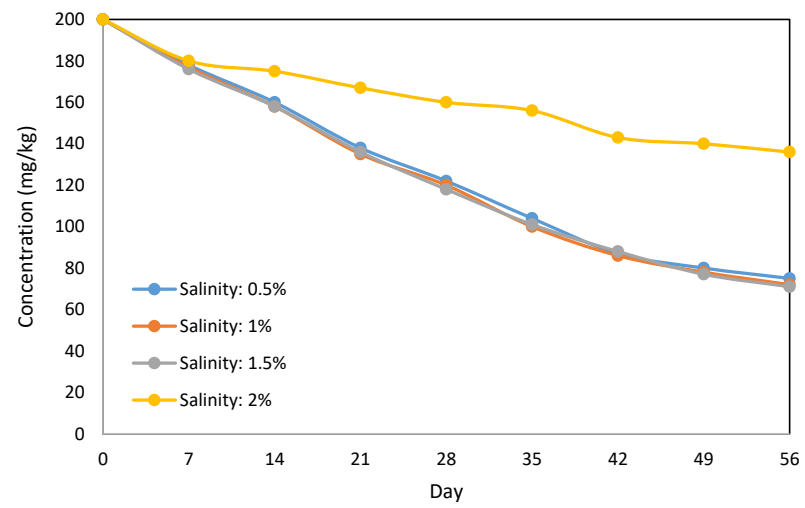

Figure 3. Effect of salinity on the biodegradation rate of in the contaminated soil by Bacillus kochii strain AHV-KH14, seed size: $10 \mathrm{~mL}$, moisture: slurry.

rate during the bioremediation process. As shown in this figure, the TPH mineralization rate was lower than the PHE removal due to the conversion of mother compound (PHE) to biodegradation metabolites. In this regard, the mineralization rate reached $39 \%$ at the end of day 56 , compared to the removal rate of $64 \%$ for the PHE at the same condition.

\section{Discussion}

\section{Bacterial strain}

Based on the 16S rRNA gene sequences and Neighborjoining phylogenetic analysis (Figure 6), the bacterial isolate was characterized as Bacillus kochii strain AHVKH14. This strain is a gram-positive, strictly aerobic, motile, catalase-positive, endospore-forming rods, and halo-tolerant bacterium. Its sequence was registered in Genbank under accession number of MH819661.

Neighbor-joining method with MEGA 6.0 was applied for constructing tree. Bootstrap values over 70\% (1000 replications) were indicated at each node. Escherichia coli (LN831047) was used as the out-group.

Bioremediation of PHE-contaminated soil Effect of seed size

According to the results, inoculum size was effective
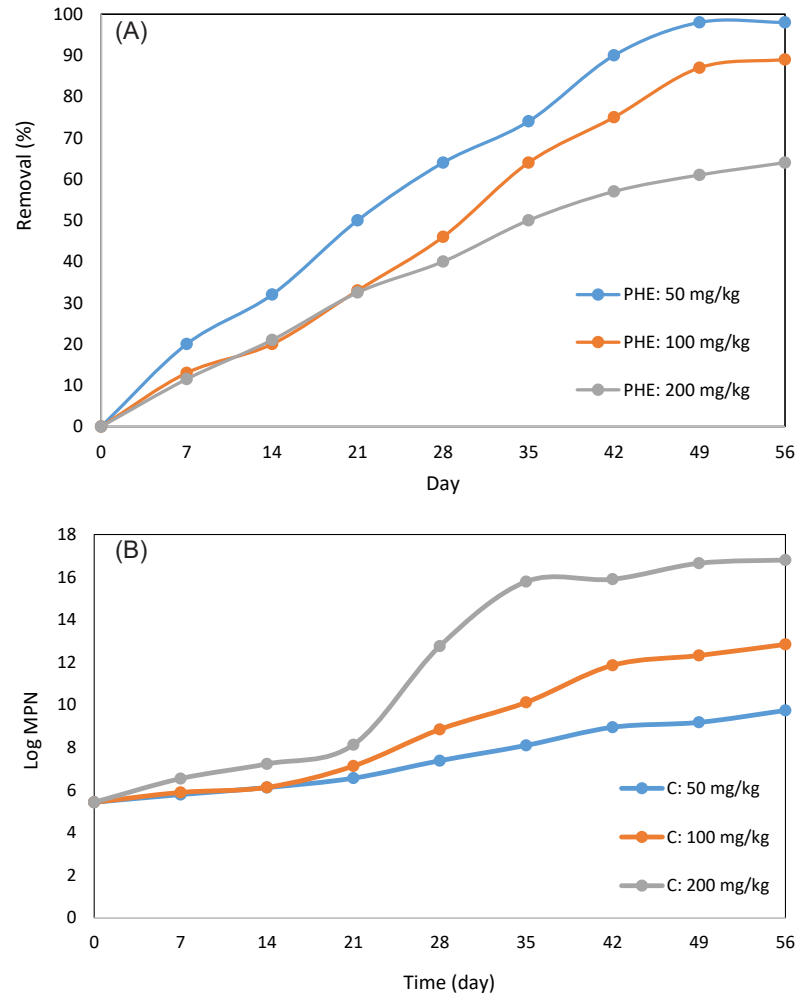

Figure 4. (A) Effect of PHE concentration on the biodegradation efficiency in the contaminated soil by Bacillus kochii strain AHV-KH14 (seed size: 10 $\mathrm{mL}$, slurry phase, salinity: $1.5 \%)$, (B) Comparison of bacterial density in different initial PHE concentrations.

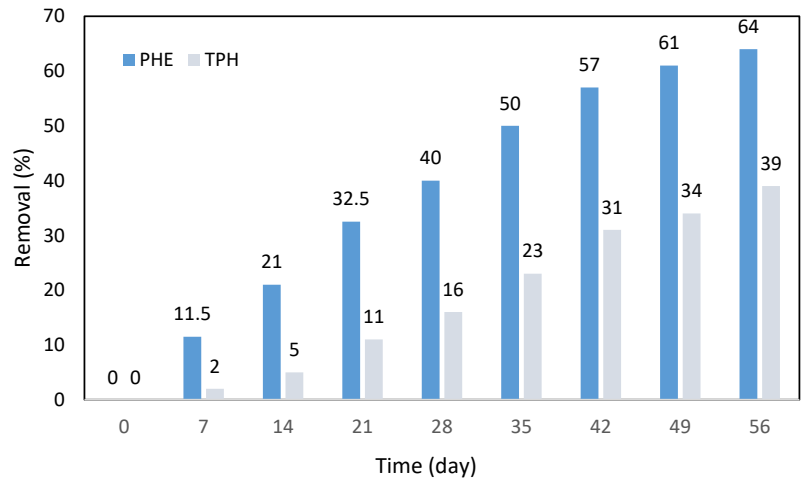

Figure 5. Mineralization rate of PHE in the synthetically contaminated soil by Bacillus kochii strain AHV-KH14 (seed size: $10 \mathrm{~mL}$, slurry phase, salinity: $1.5 \%$, PHE: $200 \mathrm{mg} / \mathrm{kg}$ ).

on the biodegradation rate. At the initial steps and due to low bacterial density in the bioreactor, the startup of biological reaction was slow and vice versa. The PHE removal enhanced with increase of seed size till the value of $10 \mathrm{~mL}$, and there was no significant increase in the biodegradation rate at higher levels (Figure 1). Adaptation period of biomass to PHE as well as low bacterial density in lag phase of growth leads to low biodegradation rate in the initial steps. By increasing the bacterial density at startup, the biodegradation rate could be enhanced somewhat, but from a break point which was $10 \mathrm{~mL}$ in the present study, 


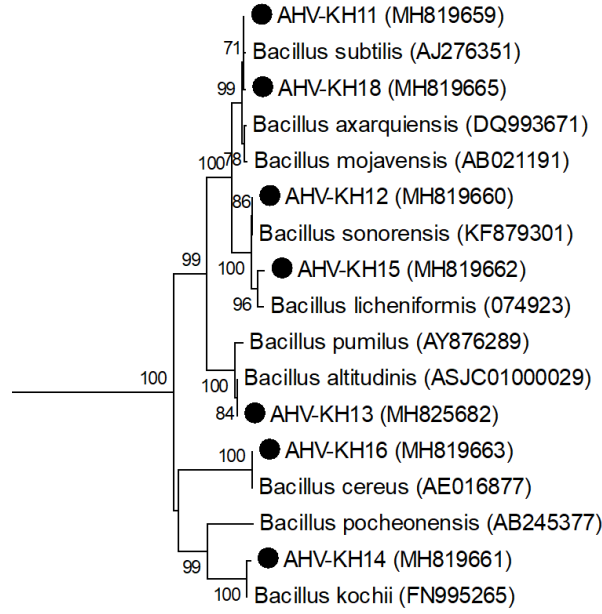

Figure 6. Phylogenetic tree of $16 \mathrm{~s}$ rRNA sequences.

increasing the seed size will not affect the biodegradation rate due to lack of substrate and intensive competition, which in turn, leads to a sufficient metabolism $(17,18)$. According to literature, a successful strategy to enhance the performance of slurry bioreactors treating hydrocarbons is bioaugmentation (19). Therefore, B. kochii strain AHVKH14 was efficient in the biodegradation of PHE with seed size of $10 \mathrm{~mL}\left(\mathrm{OD}_{600}=1\right)$, corresponding to $\log \mathrm{MPN}$ value of 5.43. The PHE biodegradation efficiencies (200 $\mathrm{mg} / \mathrm{kg}$,) at the end of day 56 were $30,35,35.5$, and $36 \%$, for the inoculum sizes of $5,10,15$, and $20 \mathrm{~mL}$, respectively. As there was no significant difference between 10, 15, 20 $\mathrm{mL}$ of seed size $(P>0.05)$, the value of $10 \mathrm{~mL}$ was chosen for the remaining experiments, which is consistent with the results of the study of Zhao et al (20). Qin et al also demonstrated higher biodegradation rates of hydrocarbons for high levels of microbial inoculation (21).

\section{Effect of moisture content}

The soil moisture, which is affected by soil texture and organic matter contents, influences the biodegradation rate significantly, since the uniform distribution of substrate and nutrients and even biomass is controlled by water in soil (22). Bioavailability of substrate and its solubility is a major issue for the biodegradation of recalcitrant hydrocarbons by bacterial consortiums and as mentioned before, a uniform environment, in terms of oxygen, bacterial mass, macro and micro nutrients, and target hydrocarbon in a high-gradient medium, such as soil, is provided by moisture (23). Sorption and transportation of metabolic by-products into or out of the bacterial cell is also affected by water in the reaction medium. Consequently, a successful biodegradation is strongly related to water content of the soil (24). Since the soil/water ratio affects the mass transfer in the slurry phase bioreactor, therefore, a desired removal rate can be attributed to water content (25). The PHE biodegradation efficiencies at different moisture levels of 50\%, 100\%, and $200 \%$ (slurry) were $23 \%, 35.5 \%$, and $62.5 \%$, respectively
(Figure 2). According to the results, the PHE removal was improved in the slurry phase, which facilitates the metabolism function of $B$. kochii strain AHV-KH14 through enhancing the bioavailability of PHE in soil, which is consistent with the results of some studies $(26,27)$. Previous studies on the effect of water content on biodegradation rate indicated that high moisture content improved the hydrocarbon removal in a bioremediation experiment $(28,29)$.

\section{Effect of salinity}

Effect of soil salinity on the PHE biodegradation rate was also studied. High salinity levels can adversely affect the biodegradation of organics in soil. Reports indicate that salinity, such as $\mathrm{NaCl}$, can disturb both metabolism and growth simultaneously (30). The PHE removals (concentration of $200 \mathrm{mg} / \mathrm{kg}$ ) at the end of day 56 were $62.5 \%, 64 \%, 64.5 \%$, and $32 \%$ for salinity levels of $0.5 \%, 1 \%$, $1.5 \%$, and $2 \%$, respectively (Figure 3 ).

The results indicated the adverse effect of salinity level of $2 \%$ on the PHE biodegradation. Since in this study, bioremediation in saline environment was preferred due to similarity to real conditions and observation of no significant difference between removal data of other salinity levels $(P>0.05)$, remaining experiments were conducted in salinity level of $1.5 \%$. Findings of the present study indicated that the biodegradation of PHE in the contaminated soil was correlated with salinity up to $1.5 \%$, and in higher salinity values, the metabolic function of B. kochii strain AHV-KH14 was destroyed (31), which is consistent with the results of similar studies about effect of salinity on the bioremediation of hydrocarboncontaminated soils (32).

\section{Effect of PHE concentration}

Concentration of PHE affected the biodegradation ability of B. kochii strain AHV-KH14. According to the obtained results, as the PHE concentration was increased, the removal efficiency by biodegradation was decreased, but the toxic level and inhibitory level were not observed in the PHE concentrations of $50-200 \mathrm{mg} / \mathrm{kg}$ (Figure 4A), which indicates the high metabolic function of the isolated strain (B. kochii strain AHV-KH14). Related studies have also verified the adverse effect of high concentrations of organic substrate on the microbial consortium and biodegradation efficiency (33). The removal efficiency of PHE for the initial concentrations of 50, 100, and $200 \mathrm{mg} /$ $\mathrm{kg}$ (dry weight) were $98 \%, 89 \%$, and $64 \%$, respectively at the end of day 56 . Researchers have specially reported that the elevated hydrocarbon concentrations are toxic and inhibit the biologic reactions (34). There are some claims for decreasing biodegradation with increasing the initial concentration of pollutant, when it would be adsorbed on the soil particle surface, which hinders the microbial growth and causes toxic effects, which decrease microbial activity, slow metabolism rate, and thus, exhausts the 
survival ability of microbial populations (35). Despite of lower removal rate for the initial PHE concentration of 200 $\mathrm{mg} / \mathrm{kg}$, around $128 \mathrm{mg} / \mathrm{kg}$ substrate was degraded, which is considerable. This acceptable performance of $B$. kochii strain AHV-KH14 could be attributed to the appearance of a higher bacterial density when a high concentration of carbon source is present. As illustrated in Figure 4B, bacterial density for the initial PHE concentration of 200 $\mathrm{mg} / \mathrm{kg}$ was significantly higher, compared to the two other levels.

\section{PHE mineralization}

Mineralization of PHE was studied using a comparative analysis of PHE and TPH. As can be seen in Figure 5, the TPH removal is lower than the PHE removal due to the conversion of mother compound (PHE) to biodegradation metabolites. In this regard, the mineralization rate reached $39 \%$ at the end of day 56, compared to the removal rate of $64 \%$ for PHE at the same condition, which is consistent with the results of the study of Jorfi et al (36).

\section{Bioremediation of unwashed soil}

Reliability of the isolated halo-tolerant strain (B. kochii strain AHV-KH14) in the biodegradation of various petroleum hydrocarbons in a real unwashed contaminated soil was also evaluated under selected conditions. As shown in Figure 7, a wide range of different n-alkanes were present in the polluted soil sample. The initial TPH concentration of $2350 \mathrm{mg} / \mathrm{kg}$ decreased to $1845 \mathrm{mg} / \mathrm{kg}$ (dry weight) (17.7\% removal) during 56 days. Unwashed soil was contaminated with 1,2-benzenedicarboxylic acid, octadecane, hexadecane, pentadecane, nonadecane, tetradecane, and cyclotrisiloxane, and a low concentration of PAHs. The variety of contamination and high cumulative concentrations of different hydrocarbons in the unwashed soil were the main reasons for lower removal efficiency of the isolated strain compared to synthetically contaminated samples, which is consistent with the results of a study on the purification of hydrocarbon-polluted soil $(37,38)$.

\section{Conclusion}

In this study, a halo-tolerant bacterium, Bacillus kochii strain AHV-KH14, was isolated from municipal compost, and then, used for the bioremediation of PHE from contaminated soil. A biodegradation efficiency up to $98 \%$ was observed for the initial PHE concentration of $50 \mathrm{mg} / \mathrm{kg}$ and salinity level of $1.5 \%$, and the biodegradation efficiency decreased significantly with increasing salt concentration. The findings showed that the bioremediation efficiency decreased with increasing PHE concentration. The results also indicated that a variety of contaminants and high cumulative concentrations of different hydrocarbons in unwashed soil had a main role in decreasing the efficiency of bioremediation. A natural hydrocarbon-contaminated soil sample with TPH concentration of $2350 \mathrm{mg} / \mathrm{kg}$ was

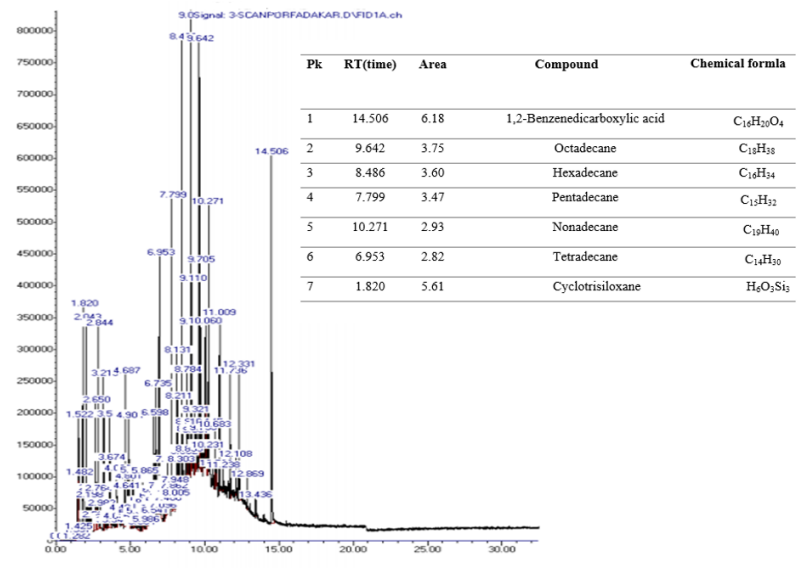

Figure 7. The GC-MS analysis of unwashed hydrocarbon-contaminated soil.

subjected to bioremediation using the selected conditions of operational parameters, and a biodegradation rate of $17.7 \%$ was obtained. Finally, GC-MS analysis was performed to study changes in PAHs, and it was concluded that the variety of contamination and high cumulative concentrations of different hydrocarbons in unwashed soil are the main reasons for lower removal efficiency of the isolated strain compared to those of synthetically contaminated soil.

\section{Acknowledgments}

The authors would like to gratitude Ahvaz Jundishapur University of Medical Sciences for its financial support (Grant No: 96s64).

\section{Ethical issues}

The authors hereby certify that all data collected during the research are as expressed in the manuscript, and no data from the study has been or will be published elsewhere separately.

\section{Competing interests}

The authors declare that they have no conflict of interests.

\section{Authors' contributions}

All authors have contributed in the study design, experiments, data collection and analysis, and manuscript preparation. The final version of this manuscript was reviewed and confirmed by all authors.

\section{References}

1. Jorfi S, Pourfadakari S, Ahmadi M. Electrokinetic treatment of high saline petrochemical wastewater: evaluation and scale-up. J Environ Manage 2017; 204(Pt 1): 221-9. doi: 10.1016/j.jenvman.2017.08.058.

2. Honda K, Mizukami M, Ueda Y, Hamada N, Seike N. Residue level of polycyclic aromatic hydrocarbons in Japanese paddy soils from 1959 to 2002. Chemosphere 2007; 68(9): 1763-71. doi: 10.1016/j.chemosphere.2007.03.040. 
3. Tsapakis M, Stephanou EG. Occurrence of gaseous and particulate polycyclic aromatic hydrocarbons in the urban atmosphere: study of sources and ambient temperature effect on the gas/particle concentration and distribution. Environ Pollut 2005; 133(1): 147-56. doi: 10.1016/j. envpol.2004.05.012.

4. Abdel-Shafy HI, Mansour MS. A review on polycyclic aromatic hydrocarbons: source, environmental impact, effect on human health and remediation. Egypt J Petrol 2016; 25(1): 107-23. doi: 10.1016/j.ejpe.2015.03.011.

5. Alawi MA, Azeez AL. Study of polycyclic aromatic hydrocarbons (PAHs) in soil samples from Al-Ahdab oil field in Waset Region, Iraq. Toxin Rev 2016; 35(3-4): 69-76. doi: $\quad 10.1080 / 15569543.2016 .1198379$.

6. Ying GG. Remediation and Mitigation Strategies. In: Maestroni B, Cannavan A, ed. Integrated Analytical Approaches for Pesticide Management. India: Academic Press; 2018. p. 207-17.

7. Hesham Ael L, Khan S, Tao Y, Li D, Zhang Y, Yang M. Biodegradation of high molecular weight PAHs using isolated yeast mixtures: application of meta-genomic methods for community structure analyses. Environ Sci Pollut Res Int 2012; 19(8): 3568-78. doi: 10.1007/s11356012-0919-8.

8. Abatenh E, Gizaw B, Tsegaye Z, Wassie M. Application of microorganisms in bioremediation-review. Journal of Environmental Microbiology 2017; 1(1): 2-9.

9. Simarro R, Gonzalez N, Bautista LF, Molina MC. Assessment of the efficiency of in situ bioremediation techniques in a creosote polluted soil: change in bacterial community. J Hazard Mater 2013; 262: 158-67. doi: 10.1016/j.jhazmat.2013.08.025.

10. Lin C, Gan L, Chen ZL. Biodegradation of naphthalene by strain Bacillus fusiformis (BFN). J Hazard Mater 2010; 182(1-3): 771-7. doi: 10.1016/j.jhazmat.2010.06.101.

11. Bhatnagar S, Kumari R. Bioremediation: a sustainable tool for environmental management-a review. Annual Research \& Review in Biology 2013; 3(4): 974-93.

12. Cubitto MA, Moran AC, Commendatore M, Chiarello MN, Baldini MD, Sineriz F. Effects of Bacillus subtilis O9 biosurfactant on the bioremediation of crude oil-polluted soils. Biodegradation 2004; 15(5): 281-7. doi: 10.1023/b:bio d.0000042186.58956.8f.

13. Jorfi S, Rezaee A, Mobeh-Ali GA, Jaafarzadeh NA. Application of biosurfactants produced by Pseudomonas aeruginosa SP4 for bioremediation of soils contaminated by pyrene. Soil and Sediment Contamination: An International Journal 2013; 22(8): 890-911. doi: 10.1080/15320383.2013.770439.

14. Pourfadakari S, Ahmadi M, Jaafarzadeh N, Takdastan A, Neisi AA, Ghafari S, et al. Remediation of PAHs contaminated soil using a sequence of soil washing with biosurfactant produced by Pseudomonas aeruginosa strain PF2 and electrokinetic oxidation of desorbed solution, effect of electrode modification with $\mathrm{Fe} 3 \mathrm{O} 4$ nanoparticles. J Hazard Mater 2019; 379: 120839. doi: 10.1016/j. jhazmat.2019.120839.

15. Lane DJ. 16S/23S rRNA sequencing. In: Stackebrandt E, Goodfellow M, eds. Nucleic Acid Techniques in Bacterial Systematics. New York: John Wiley \& Sons; 1991. p. 115.
16. Kalantary RR, Badkoubi A, Mohseni-Bandpi A, Esrafili A, Jorfi S, Dehghanifard E, et al. Modification of PAHs Biodegradation with Humic Compounds. Soil Sediment Contam 2013; 22(2): 185-98. doi: $10.1080 / 15320383.2013 .722139$.

17. American Public Health Association, American Water Works Association. Standard methods for the examination of water and wastewater. 23rd ed. Washington, DC: American Public Health Association; 2005.

18. Leahy JG, Colwell RR. Microbial degradation of hydrocarbons in the environment. Microbiol Rev 1990; 54(3): 305-15.

19. Pino-Herrera DO, Pechaud Y, Huguenot D, Esposito G, van Hullebusch ED, Oturan MA. Removal mechanisms in aerobic slurry bioreactors for remediation of soils and sediments polluted with hydrophobic organic compounds: an overview. J Hazard Mater 2017; 339: 427-49. doi: 10.1016/j.jhazmat.2017.06.013.

20. Zhao HP, Wu QS, Wang L, Zhao XT, Gao HW. Degradation of phenanthrene by bacterial strain isolated from soil in oil refinery fields in Shanghai China. J Hazard Mater 2009; 164(2-3): 863-9. doi: 10.1016/j.jhazmat.2008.08.098.

21. Qin X, Tang JC, Li DS, Zhang QM. Effect of salinity on the bioremediation of petroleum hydrocarbons in a salinealkaline soil. Lett Appl Microbiol 2012; 55(3): 210-7. doi: 10.1111/j.1472-765X.2012.03280.x.

22. Pant A, Rai JP. Bioremediation of chlorpyrifos contaminated soil by two phase bioslurry reactor: processes evaluation and optimization by Taguchi's design of experimental (DOE) methodology. Ecotoxicol Environ Saf 2018; 150: 305-11. doi: 10.1016/j.ecoenv.2017.12.052.

23. Chibwe L, Davie-Martin CL, Aitken MD, Hoh E, Massey Simonich SL. Identification of polar transformation products and high molecular weight polycyclic aromatic hydrocarbons (PAHs) in contaminated soil following bioremediation. Sci Total Environ 2017; 599-600: 1099-107. doi: 10.1016/j.scitotenv.2017.04.190.

24. Pawar RM. The effect of soil $\mathrm{pH}$ on degradation of polycyclic aromatic hydrocarbons (PAHs) [dissertation]. United Kingdom: University of Hertfordshire; 2012.

25. Odukkathil G, Vasudevan N. Residues of endosulfan in surface and subsurface agricultural soil and its bioremediation. J Environ Manage 2016; 165: 72-80. doi: 10.1016/j.jenvman.2015.09.020.

26. Weber WJ Jr, Kim HS. Optimizing contaminant desorption and bioavailability in dense slurry systems. 1. Rheology, mechanical mixing, and PAH desorption. Environ Sci Technol 2005; 39(7): 2267-73. doi: 10.1021/es049565b.

27. Venkata Mohan S, Ramakrishna M, Shailaja S, Sarma PN. Influence of soil-water ratio on the performance of slurry phase bioreactor treating herbicide contaminated soil. Bioresour Technol 2007; 98(13): 2584-9. doi: 10.1016/j. biortech.2006.09.018.

28. Rehmann L, Prpich GP, Daugulis AJ. Remediation of PAH contaminated soils: application of a solid-liquid two-phase partitioning bioreactor. Chemosphere 2008; 73(5): 798-804. doi: 10.1016/j.chemosphere.2008.06.006.

29. Saez JM, Álvarez A, Benimeli CS, Amoroso MJ. Enhanced lindane removal from soil slurry by immobilized Streptomyces consortium. Int Biodeterior Biodegradation 
2014; 93: 63-9. doi: 10.1016/j.ibiod.2014.05.013.

30. Shetaia YM, El Khalik WA, Mohamed TM, Farahat LA, ElMekawy A. Potential biodegradation of crude petroleum oil by newly isolated halotolerant microbial strains from polluted Red Sea area. Mar Pollut Bull 2016; 111(1-2): 43542. doi: 10.1016/j.marpolbul.2016.02.035.

31. Ulrich AC, Guigard SE, Foght JM, Semple KM, Pooley K, Armstrong JE, et al. Effect of salt on aerobic biodegradation of petroleum hydrocarbons in contaminated groundwater. Biodegradation 2009; 20(1): 27-38. doi: 10.1007/s10532008-9196-0.

32. Børresen MH, Rike AG. Effects of nutrient content, moisture content and salinity on mineralization of hexadecane in an Arctic soil. Cold Reg Sci Technol 2007; 48(2): 129-38. doi: 10.1016/j.coldregions.2006.10.006.

33. Östberg TL, Jonsson AP, Bylund D, Lundström US. The effects of carbon sources and micronutrients in fermented whey on the biodegradation of $\mathrm{n}$-hexadecane in diesel fuel contaminated soil. Int Biodeterior Biodegradation 2007; 60(4): 334-41. doi: 10.1016/j.ibiod.2007.05.007.

34. Dibble JT, Bartha R. Effect of environmental parameters on the biodegradation of oil sludge. Appl Environ Microbiol
1979; 37(4): 729-39.

35. Tayybi T, Jorfi S, Ghaffari S, Kujlu R. Bioremediation of n-hexadecane contaminated soils using pseudomonas aeruginosa bacteria isolated from coastal areas. Journal of Mazandaran University of Medical Sciences 2016; 26(140): 127-36. [In Persian].

36. Jorfi S, Samaei MR, Darvishi Cheshmeh Soltani R, Talaie Khozani A, Ahmadi M, Barzegar G, et al. Enhancement of the bioremediation of pyrene-contaminated soils using a hematite nanoparticle-based modified Fenton oxidation in a sequenced approach. Soil Sediment Contam 2017; 26(2): 141-56. doi: 10.1080/15320383.2017.1255875.

37. Kulik N, Goi A, Trapido M, Tuhkanen T. Degradation of polycyclic aromatic hydrocarbons by combined chemical pre-oxidation and bioremediation in creosote contaminated soil. J Environ Manage 2006; 78(4): 382-91. doi: 10.1016/j. jenvman.2005.05.005.

38. Pan X, Liu J, Zhang D. Binding of phenanthrene to extracellular polymeric substances (EPS) from aerobic activated sludge: a fluorescence study. Colloids Surf B Biointerfaces 2010; 80(1): 103-6. doi: 10.1016/j. colsurfb.2010.05.002. 